\title{
BMJ Open Psychological distress and quality of life: rationale and protocol of a prospective cohort study in a rural district in Bangaladesh
}

\author{
Mohammed Nazim Uddin, ${ }^{1}$ Sunil Bhar, ${ }^{2}$ Abdullah Al Mahmud, ${ }^{3}$ \\ Fakir M Amirul Islam ${ }^{1,4}$
}

To cite: Uddin MN, Bhar S, Al Mahmud A, et al. Psychological distress and quality of life: rationale and protocol of a prospective cohort study in a rural district in Bangaladesh. BMJ Open 2017;7:e016745. doi:10.1136/ bmjopen-2017-016745

- Prepublication history for this paper is available online. To view these files please visit the journal online (http://dx.doi. org/10.1136/bmjopen-2017016745).

Received 16 March 2017 Revised 26 May 2017 Accepted 27 June 2017

\section{CrossMark}

${ }^{1}$ Department of Statistics, Data Science and Epidemiology, Swinburne University of Technology, Hawthorn, Victoria, Australia

${ }^{2}$ Department of Psychological Sciences, Swinburne University of Technology, Hawthorn, Victoria, Australia

${ }^{3}$ Centre for Design Innovation (CDI), School of Design, Swinburne University of Technology, Hawthorn, Victoria, Australia

${ }^{4}$ Organisation for Rural Community Development (ORCD), Narail, Bangladesh

Correspondence to Dr Fakir M Amirul Islam; fislam@swin.edu.au

\section{ABSTRACT}

Introduction A significant proportion of the global burden of disease has been attributed to mental and behavioural disorders. People with mental disorders (MDs) have lower levels of health-related quality of life than those without MDs. Several studies have shown that in low-resource countries, a range of social determinants including poor health literacy is critical in the epidemiological transition of disease outcome. There is a lack of evidence of MDs literacy, the prevalence and risk factors of common mental health conditions, or any validated instruments to measure psychological distress or evaluate the quality of life in rural areas of Bangladesh.

Aims The aims of this study are: (1) report the awareness, knowledge, attitudes and practice (KAP) of MDs; (2) estimate the prevalence of and risk factors for psychological distress; (3) measure association of psychological distress and other socio-demographic factors with quality of life and (4) test the feasibility to use Kessler 10-item (K10) and WHO Quality Of Life-BREF (WHOQOL-BREF) questionnaires in rural Bangladesh for measuring psychological distress and quality of life. Methods and analysis A sample of 1500 adults aged 18-59 years and 1200 older adults aged $60-90$ years will be interviewed from a multistage cluster random sample.

Each participant will go through a face-to-face interview to assess their awareness and KAP of MDs. Information about the participant's sociodemographic and socioeconomic status will be collected along with the psychological distress (K10) and quality of life (WHOQOL-BREF) questionnaires. Internal consistency, validity, reliability and item discrimination of $\mathrm{K} 10$ and WHOQOL-BREF instruments will be determined by using Rasch analysis and regression techniques.

Ethics and dissemination Human Ethics Approval was received from the Swinburne University of Technology Human Ethics Committee. Results of this research will be disseminated via scientific forums including peerreviewed publications and presentations at national and international conferences.

\section{BACKGROUND}

\section{Mental disorders}

Mental disorders (MDs) are one of the leading contributors to the global burden of
Strengths and limitations of this study

- This study will be conducted using a large and representative sample from a typical rural district to report the awareness, knowledge, attitudes and practice about mental disorders. Therefore, the study will provide a unique opportunity to assess the gaps in public awareness of mental disorders in rural Bangladesh.

- Data will be collected through a face-to-face interview process which will reduce the possible response bias given the literacy level is different in men and women and in different age groups.

- The study will be able to estimate the prevalence of the factors associated with psychological distress to conduct appropriate intervention programmes.

- The study will use a sophisticated Rasch analysis technique to validate the psychometric properties of the WHO Quality Of Life-BREF and Kessler 10item questionnaires for their use in Bangladesh. The study will provide the first validated tools to measure psychological distress and quality of life in the rural areas of Bangladesh, which can be used in other developing countries with the similar socioeconomic conditions.

- This study may suffer from the external validity as it is based on one area of rural Bangladesh. The study could be repeated using a random sample of other remote areas to better portrait the intensity of psychological distress and quality of life at the national level.

disease in both high-income and low-income countries, accounting for $13 \%$ of disease measured as disability-adjusted life years. ${ }^{1}$ Common types of MDs include conditions such as major depressive disorders, bipolar disorders, anxiety disorders, psychotic disorders and substance use disorders. ${ }^{2}$ Of these, major depressive and anxiety disorders contribute to approximately $50 \%$ of the international disease burden. ${ }^{3}$ Such conditions are frequently comorbid with other health and psychosocial problems and are 
among the most serious causes of morbidity. ${ }^{4-6}$ Despite the adverse impacts of such mental health conditions, they receive little attention in most of the low-income and middle-income countries, and hence, treatment of such conditions is not considered national health priority. ${ }^{78}$ Mental health complaints create a major public health concern in Bangladesh, especially in rural areas. ${ }^{4910}$ The prevalence of MDs in such areas varies between $6.5 \%$ and $31 \%$ possibly due to the use of different protocol and definitions of MDs. ${ }^{11}$

\section{Factors associated with MDs}

A number of factors have been identified as increasing risks for MDs. These factors include a lack of access to, and usage of, mental health services, stigma about mental health treatment and poor physical health. ${ }^{12}$ MDs are present to a greater extent among low socioeconomic status (SES) groups, ${ }^{13}$ and research shows that financially poor countries with poor health literacy are critical in the epidemiological transition of disease outcome. ${ }^{14-18}$ A lot of evidence supports that KAP studies are needed for greater awareness of prevention, diagnosis, risk factor control and disease management of psychological distress. $^{14-21}$

Mental health literacy has been defined as 'knowledge and attitudes about MDs which aid their recognition, management and/or prevention' ${ }^{22}$ Knowledge and positive attitudes towards treatment are fundamental for individuals seeking help for MDs in a timely and appropriate manner. In India, recent studies have reported limited knowledge of mental health issues and high rates of negative attitudes towards seeking help responsible for mental health problems, ${ }^{23}{ }^{24}$ yet similar literature for the neighbouring region of Bangladesh is lacking.

\section{Quality of life}

In recent years, beyond traditional health indicators such as mortality and morbidity, there has been a greater focus on measuring health and quality of life (QOL) as important outcomes in clinical and interventional studies. ${ }^{25}$ QOL is used as an important outcome measure for evaluating intervention effects, such as the effect of medicine. ${ }^{26}$ The WHO defines QOL as 'individuals' perception of their position in life in the context of the culture in which they live and the value systems they have in relation to their goals, expectations, standards and concerns'. ${ }^{27}$

The QOL is affected by a range of factors such as physical health, psychological state, level of independence, social relationships, personal beliefs and their relationships with silent features of their environment. ${ }^{28}$ However, most of the research on QOL is focused on the deleterious impact of chronic physical health diseases such as cancer, stroke, diabetes and HIV/AIDS. ${ }^{29-32}$ Furthermore, over the past 20 years, although a quite a number of tools have been developed to measure QOL, ${ }^{33}$ with a few exceptions, ${ }^{34-36}$ these measure of QOL are impacted by specific diseases. As an exception, the QOL Scale (QOLS) first developed by American psychologist, John Flanagan, ${ }^{37} 38$ fits a more generalised definition of QOL that can be used to assess QOL in an everyday context. The WHO Quality Of Life-BREF (WHOQOL-BREF) is a shortened version of 26-item instrument, rated on 5-point Likerttype scales, used for large population studies. ${ }^{39}$ This tool has not been applied to a general population setting in any developing countries, including Bangladesh.

A Bengali version of the WHOQOL-BREF was initially developed in 2005 for using in a study of adolescents and adults, residing only in the capital city of Bangladesh, Dhaka. ${ }^{40}$ The Bengali version of the scale has been used in some rural areas of the country since 2005. ${ }^{42} 43$ The dimensionality of the Bengali version of WHOQOLBREF was assessed using a classical test theory (CTT). ${ }^{40} 41$ In CTT approach, the items and the person latent trait are measured separately and descriptive measures are provided. In the CTT method, true score estimates are typically obtained by summing the responses across items, with the assumption that each item within the same construct is valued equally. A further assumption of the CTT is that the score difference between the two adjacent response scales is uniform although this does not occur in all circumstances. ${ }^{44}$ Therefore, the CTT cannot be meaningfully and methodically compared in an item-person continuum. ${ }^{45} 46$ These restrictions can be resolved using item response theory (IRT) modelling (Rasch analysis) despite IRT's own assumptions regarding unidimensionality, invariability and local independence. ${ }^{45} 46$

\section{Psychological distress}

In recent years, epidemiological studies have attempted to use less items to proficiently measure and monitor the extent of psychological distress in the widespread community. ${ }^{47}$ For the purpose of measuring depression and anxiety few scales have been used so far. These include the Beck Depression Inventory, ${ }^{48}$ the Hospital Anxiety and Depression Scale, ${ }^{49}$ the Depression Anxiety Stress Scales $^{50}$ and the Kessler 10-item (K10) Scale. ${ }^{51}$ The K10 is one of the most popular tools for screening psychological distress in the general population. ${ }^{52} \mathrm{~K} 10$ comprises 10 items, rated on 5-point Likert-type scales, which indicate the degree of psychological distress prevalent among persons. ${ }^{51}$ The K10 has been established predominantly from western population samples. ${ }^{51-56}$ Information on cross-cultural validity of the K10 is not available in Bangladesh. Therefore, we have used an interview-administered version of K10 in our study due to the low rate of literacy in Bangladesh. ${ }^{57}$

\section{Reliability and validity of K10 and WHOQOL questionnaires}

Reliability and validity are context-specific attributes, showing applicability to some populations over others. As the QOL and physiological distress assessment instruments are used in a variety of cultural settings, it is important to establish whether the same aspects of life are equally important for adults across the lifespan, men and women, people with and without education and for 
people with various relationship and employment status. The above factors report to impact differently on people's lives, but how significant these differences are and the issue of whether a reasonably valid tool can be developed in spite of these differences need to be addressed in Bangladesh. ${ }^{58}$ Therefore, the validation of the WHOQOL questionnaire as well as the K10 questionnaire in a general population, both in adults and older adults, can provide the empirical development of the literature on these issues in Bangladesh.

\section{Aims of the study}

The current prospective cohort study will be conducted in a rural district of Bangladesh to address a number of research questions and the specific aims are as follows:

1. Report the awareness, knowledge, attitudes and practice using seven items from the mental health literacy questionnaire of mental disorders.

2. Estimate the prevalence of psychological distress in both adults and older adults according to sociodemographic status.

3. Estimate the quality of life in adults and older adults, their risk factors and the variation according to the sociodemographic factors.

4. Measure the association between psychological distress with the quality of life.

5. To test the internal validity of the K10 scale using Rasch analysis.

6. To investigate the factor structure of K10 scale using confirmatory factor analysis (CFA) and exploratory factor analysis (EFA).

7. To test the internal validity of the four-domain WHOQOL-BREF questionnaire using Rasch analysis.

8. To assess the factor structure of the WHOQOL-BREF in a Bangladeshi rural general population sample using CFA and EFA.

\section{METHODS}

\section{Study population}

Bangladesh is a country of 160 million people divided into 64 districts. Each district is divided into subdistricts named upazilas (493 in total), and each upazila further divided into several unions and the city centre known as pourashava. Each union consists of 15-25 villages and the pourashava consists of $5-15$ wards which are divided into localities (also known as 'para' in Bengali) that are comprised of several households. Participants will be recruited from the Narail district (figure 1). Narail is located approximately $200 \mathrm{~km}$ southwest of Dhaka, the capital city of Bangladesh. The population of Narail upazila is 272872 , with approximately $40 \%$ of residents aged between 18 and 59 years and 19000 (about 7\%) of residents aged between 60 and 90 years. The study location was selected as it was considered to be representative of a typical rural demographic in Bangladesh. The area of Narail upazila is $381.76 \mathrm{~km}^{2}$, located in between $23^{\circ} 02^{\prime}$ and $23^{\circ} 17^{\prime}$ north latitudes and in between $89^{\circ} 23^{\prime}$ and $89^{\circ} 37^{\prime}$ east longitudes. It is bounded by Lohagara and Salikha upazilas on the north, Kalia and Abhaynagar upazilas on the south, Lohagara upazila on the east, and Bagherpara and Jessore Sadar upazilas on the west. The district consists of 13 unions, 231 villages, 1 pourashava and 9 wards. The total population of this upazila is 273 000 with $49 \%$ men. Literacy of this upazila for men is $63.3 \%$ and women is $59.3 \%$. Here, $73 \%$ people are Muslim and approximately 27\% are Hindus. Currently, there is one 100-bed government hospital and 11 private clinics consist of 115-bed facilities. Only 36 medical doctors are working for the whole upazila and no specialised hospitals or clinic. ${ }^{59}$ The Narail upazila an estimated population density of 722 people per $\mathrm{km}^{2}$ is comparable to the national rural population density of 873 people per $\mathrm{km}^{2}$. It is not at the extremity of remote locations nor is it a catchment of a metropolis such as Dhaka. ${ }^{60}$

\section{Sample size and statistical power}

Prior data indicate that the prevalence of severe depression was $21 \%$ in older adults aged $\geq 60$ years and $6.5 \%$ in adults aged between 18 and 60 years. ${ }^{61}$ We assumed a margin of error of $5 \%$ in prevalence rates for older adults and of $3 \%$ in adults when estimating the true prevalence of severe depression for each cohort in this rural area. Using a significance level of 0.05 and statistical power $>80 \%$, a required sample size of 1128 is needed for the older adults and 1283 for the adults, respectively. We did not adjust for cluster effects because only a single participant will be recruited from each household. However, assuming non-response and other possible problems, such as irrelevant or duplicate data, erroneous or misinterpreted data and too little data acquired from the client in data collection, the sample size was adjusted. Hence, the recruitment target will be increased to 1200 older adults aged between 60 and 90 years and to 1500 adults aged between 18 and 59 years.

\section{Sampling frame}

A multistage cluster random sampling technique was used for this prospective cohort study. Three unions from a total of 13 and 1 ward from a total of 9 located within Narail District were randomly selected at level 1. Two to three villages or mahalla from each selected union or ward were randomly selected at level 2. The unions and ward are shown in figure 1. The selected villages from different unions were as follows: Banshgram union: Tabra, Betvita and Ballertop, Bhadrabila union: Ramshidi, Bogura and Palaidanga, Tularampur union: Betenga, Mitna and Bamanhat, ward 1: Kurigram and Maijpara. The projected recruitment target was set at 120 older adults and 150 adults from each village. Each village or ward comprised between 360 and 480 households and one eligible adult or older adult will be interviewed from each household.

\section{Recruitment strategy}

First, the chief investigator and the head of the Department of Statistics, Data Science and Epidemiology at 


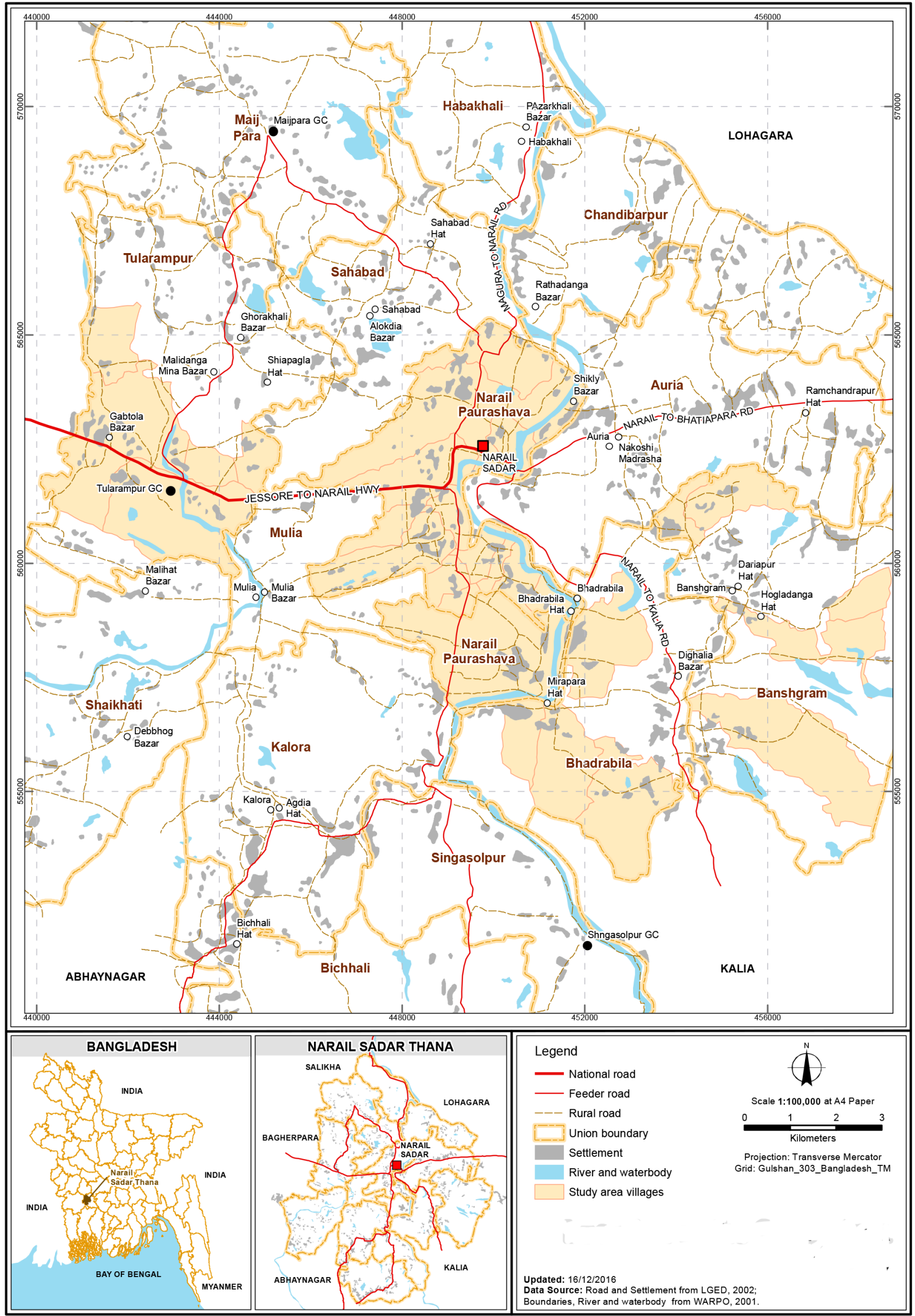

Figure 1 Location of the study area. 
the Swinburne University of Technology, Australia have sent a letter to the district commissioner, district civil surgeon, police super and chairman of the Union Parishad seeking their cooperation. Second, interviewers will provide the village leaders and/or school teachers with a general overview of the research and will request their cooperation. Once received the consent of the village leaders, the interviewer will approach the prospective participants to explain the purpose of the study and to invite them to participate in the study.

The interviewers will be instructed to interview an older adult first. If none are available in this subgroup, the interviewer will approach an adult person of that household. Again, if there will be more than one male or female adult in the same household, one individual will be selected, based on who was born closer to the month of January. However, to maintain an approximately equal number of males and female participants, one female will be interview immediately after an interview of a male participant. Selected participants of age $<18$ years or $>90$ years and having an illness will be excluded from the study.

\section{Quality assurance}

All team members will participate in an intensive 2-day training programme in Narail before the will commencement of the survey. The purpose of the training is to outline the rationale of the study, and the procedures and potential difficulties associated with data collection.

\section{DATA COLLECTION}

\section{Questionnaires}

An interviewer-administered semistructured questionnaire is being developed to collect relevant sociodemographic data and to assess participant's awareness, knowledge, attitudes and practice regarding MDs. Data will be collected through a face-to-face interview process, which will allow a greater possibility of collection of more truthful answers. Questions regarding income, financial support and consumption of tobacco will also be collected. The questionnaire is shown in table 1.

\section{Awareness, knowledge, attitude and practice about MDs}

Given the relative lack of validated mental health KAP data, the specific items included in the final questionnaire were derived from the National Survey of Mental Health Literacy and Stigma by Reavley and Jorm. ${ }^{62}$ The questionnaire will be used to assess the awareness of seven common MDs (depressive disorders, bipolar disorders, anxiety disorders, psychotic disorders and substance use disorders) by asking if they have ever heard of these diseases with a possible response of 'yes' or 'no'. Based on their responses, they will be further requested to list at least one symptom of the disease to provide insight into the level of knowledge they possessed. Attitudes towards the use of treatment will be assessed by asking the question 'do they need treatment?' with a possible response of 'yes' or 'no'. The practice about MDs will be evaluated based on whether the participant or any of his/her relatives had ever experienced any mental health problem, and from whom they would seek treatment, with a possible response of 'medical doctor', 'psychologist' or others such as 'spiritual persons'. The detail questions about KAP are reported in different sections after table 1.

Kessler psychological distress scale (K10) and WHOQOL-BREF questionnaires

The K $10^{51}$ was used to measure psychological distress and WHOQOL-BREF ${ }^{63}$ to assess the QOL of the participants. The K10 was translated into Bengali independently by two bilingual translators including a medical practitioner with experience in public health. The K10 questionnaire was translated using back-translated techniques. ${ }^{64}$ Regarding the WHOQOL questionnaire, the chief investigator (AI) contacted the original developers of the WHOQOLBREF QOL assessment test team ${ }^{65}$ to seek permission to use the Bengali version of the WHOQOL-BREF for research purposes in Bangladesh. This version was also translated to accommodate Narail languages. Validity of such translations were checked through the back-translation procedure. ${ }^{64}$

\section{Planned data collection}

Location: Narail upazila (figure 1). Duration of data collection: MayJuly 2017

\section{Outcome variables}

The first outcome variable will be the prevalence of psychological distress which will be defined based on the sum of a five-value response option for each of 10 Kessler questionnaire items, with the maximum score of 50 and the minimum score of 10 , then categorised according to the score obtained: no psychological distress (10-19), mild (20-24), moderate (25-29) and severe psychological distress (30-50).

The second outcome variables will be the prevalence of awareness of MDs comprising seven common MDs: depression, anxiety, psychosis, drug addiction, dementia, bipolar disorder and Alzheimer's disease, provided the participants have ever heard about the disorders. Prevalence of knowledge will be measured based on whether the participants are able to identify at least one symptom of the MDs and are aware of the disorders. Attitudes will be deemed positive if the participants who are aware of the MDs are in favour of taking medical treatment or psychological counselling, and practice if participants with MDs already take medical treatment or psychological counselling.

Validated K10 questionnaire: the K10 comprises 10 questions that will be answered using a 5-point scale. We will use Rasch analysis to achieve adequate model fit for K10 that will give internal consistency, reliability, unidimensionality and freedom from differential item function (DIF) for sex (man/ woman) and age (adult and elderly).

Validated WHOQOL questionnaire: to assess the QOL of rural people in Bangladesh we will use the 
Table 1 Variables will be collected for the study

\begin{tabular}{|c|c|}
\hline Variables & Measures \\
\hline \multicolumn{2}{|l|}{ Identification } \\
\hline \multicolumn{2}{|l|}{ Date of birth } \\
\hline \multicolumn{2}{|l|}{ Serial number } \\
\hline \multicolumn{2}{|l|}{ Participants name } \\
\hline Mobile number (relative) & Next of kin whom he/she can be contacted \\
\hline Father's or husband's name & $\begin{array}{l}\text { Father's name for men or unmarried men or women; husband's name for married or widowed } \\
\text { women }\end{array}$ \\
\hline Household & Household such as Fakir Bari \\
\hline Village & Village \\
\hline Age & $18-90$ years \\
\hline Sex & Woman or Man \\
\hline Educational qualification & $\begin{array}{l}\text { No schooling, 1-5 years (primary), 6-10 (below SSC pass), SSC or HSC pass, and Bachelor's } \\
\text { degree or above }\end{array}$ \\
\hline Marital status & Married (living with husband/wife), widowed, never married, divorced or separate \\
\hline Occupation & $\begin{array}{l}\text { Student, housewives, land owner, cultivates other's land, business,government or non- } \\
\text { government job, daily labour, unemployed, retired and unable to work for disability }\end{array}$ \\
\hline Socioeconomic status & $\begin{array}{l}\text { Insufficient funds all the time, insufficient funds some of the time, balanced (neither sufficient } \\
\text { nor deficit), Sufficient funds most of the time }\end{array}$ \\
\hline
\end{tabular}

HSC: higher secondary certificate; SES: socioeconomic status; SSC: secondary school certificate.

WHOQOL-BREF tool, which consists of 26 questions with structured responses on a 5-point Likert scale. Of the 26 questions, 2 assess the perception of QOL and health of the patient, and the others (24 questions) comprise the physical, psychological, social and environmental domains. Therefore, we will use Rasch analysis, confirmatory factor analysis (CFA) and exploratory factor analysis (EFA) for each domain to provide an optimal evaluation of the QOL of rural people.

\section{Exposure variables}

Demographic details for age, categorised as either adult (18-59 years) or older adult (60-90 years), gender, level of education-categorised as no schooling, primary school education (grade 1-5), secondary school education (grade 6-10) and secondary school certificate or above and SES will be collected. SES will be assessed according to Cheng et $a l^{66}$ asking whether 'over the last twelve months, in terms of household food consumption, how would you classify your SES?' The possible answers are: (1) insufficient funds for the whole year; (2) insufficient funds some of the time; (3) neither deficit nor surplus (balance) and (4) sufficient funds most of the time. Data on ongoing health conditions (yes or no), number of health problems, use of medication and smoking status are classified into three categories: 'never smoking', 'ever smoking' and 'smokeless tobacco use' will also be collected during the interview.

\section{Planned statistical analysis}

Primary objective 1: awareness, knowledge, attitude and practice of mental disorders and prevalence of psychological distress in rural area

Rasch analysis will be performed to compute the person measures based on the awareness of seven common mental disorders in a logarithmic scale and termed as 'awareness score'. Differentials of the measures of awareness, knowledge, attitudes and practice towards MDs will be evaluated across different major subdomains of age, gender, level of education and other socioeconomic factors using Pearson $\chi^{2}$ tests of independence. Multiple regression analysis techniques will be used to investigate 
the factors contributing to the combined score of awareness about the underlying MDs. Data pertaining to the awareness about MDs will be collected using the KAP questionnaire and analysed using RUMM2030 and SPSS 23 software.

An estimate of the prevalence of psychological distress will also be calculated (using standard cut-off values of a combined K10 score, according to Victorian Population Health Survey). ${ }^{67}$ Factors associated with psychological distress will be investigated using $\chi^{2}$ test and binary or multinominal logistic regression techniques.

Finally, the association between the QOL and potential contributing factors including awareness, knowledge and attitudes towards MDs and psychological distress will also be assessed using regression techniques.

\section{Primary objective 2: evaluate and validate the Kessler K10}

Rasch analysis will be used to find a possible unidimensional structure of K10. Moreover, we will use the EFA and CFA to explore the factor structure of the K10 questionnaire.

\section{Primary objective 3: evaluate and validate the WHOQOL-BREF}

Confirmatory factor analysis (CFA) will be applied to the original four domains (physical, psychological, environmental and social), assuming the orthogonally between factors and invariance of the structure across items. Rasch analysis will be used to check unidimensionality, local independence and invariability of the original four domains. If needed, we will take necessary adjustments to improve the model fit. Finally, the proposed model will be tested to get a possible psychometric structural model for the WHOQOL-BREF in the rural area in Bangladesh.

\section{Follow-up data collection}

Subjects between 18 and 90 years of age are deemed to be the appropriate target population. In Bangladesh, there is no prior longitudinal follow-up study on physiological distress and QOL. Therefore, we have used an alternative approach to measure physiological distress using the K10 questionnaire as a proxy of depression or anxiety. Prior data indicate that the prevalence of severe depression was $21 \%$ in older adults of age $\geq 60$ years and $6.5 \%$ in adults aged between 18 and 59 years.$^{61}$ Based on the prior data, we expect 2250 participants will be free from severe psychological distress at the baseline. There is no prior information to predict the incidence of psychological distress per year. However, we would expect the incidence rate of 3\%-4\% per year, indicating about 100 new cases per year. The follow-up data collection will be conducted in every 2 years from which the expected number of incidence will be sufficient to study the factors associated with the incidence of psychological distress.

Main baseline and follow-up studies are as follows: baseline: May to July 2017 (2500 samples); second follow-up: May to July 2019 (2125 participants, 85\% participation) and third follow-up: May to July 2021 (1800 participants, $85 \%$ participation). The eligible criterion will be followed from baseline. Although we acknowledge the importance of aiming for maximum follow-up in any study, in practice, it is inevitable that losses to follow-up will occur.

At the baseline, some procedure to be followed to minimise the loss of follow-up.

1. Collect baseline information, for example, addresses, phone numbers, but also for possible contacts such as next of kin or close friends.

2. When feasible, we try to involve village leaders or Union Chairmans because they are more likely to remain in that area, which makes it easier to track them down if they relocate.

3. Send participants newsletters periodically to keep them updated on the study progress.

\section{DISCUSSION}

A questionnaire that demonstrates reliability, validity and responsiveness in a certain context may not necessarily be appropriate for other contexts. The validation of the Bengali version of the K10, as well as the WHOQOL-BREF questionnaires, will enable them to be used in a broader context in which similar circumstances arise. The K10 has not been used previously in Bangladesh. Previously, the Bengali version of WHOQOL-BREE was used in a specific population such as those in slum areas ${ }^{4041}$ and on diseaseprone individuals, ${ }^{42}{ }^{43}$ which limited the validity, reliability and the general utility of the questionnaire. However, they failed to include middle-income people, general rural people and elderly people. The properties of the test may have changed as it was used to assess people who were more representative of the national socioeconomic condition during a specific period. In the present study, the inclusion of rural people aged between 18-59 and 60-90 years enhances the usefulness of the questionnaire. The validation of the Bengali versions of WHOQOLBREF and K10 are expected to enable generalisability of the scales and will allow comparisons to be made between developing countries as well as the contrast between classical test theory and item response theory.

The study will present a unique opportunity to assess the gaps in public awareness of MDs in a rural district of Bangladesh. This information would be useful in the formulation of policy for the awareness, training, management and service delivery in regards to MDs issues in rural areas of Bangladesh and may be used as a model in low-income and middle-income countries around the world. The purpose of the project is to create an opportunity to work with a local non-government organisation (the Organization for Rural Community Development) and capture information that would be of practical benefit to health policy planners in the Narail district and local health authorities. This information could ultimately benefit the general population. Moreover, another benefit of the study will be validating the psychometric properties of the WHOQOL-BREF and K1O questionnaires using the traditional CTT, Rasch analysis and EFA. These will then enable the exploration of different statistical methods in order to produce 
the best model for Bangladeshi rural population. The study will be conducted on a large sample of both adults and older adults and use face-to-face data collection. A targeted intervention might be needed to increase awareness of MDs. Moreover, we will be able to determine the proportions of rural populations who experience physiological distress and to explore most common socioeconomic factors that drive psychological distress. This will help us identify the potential socioeconomic factors that can be targeted initially. The study will explore how many items of the K10 scale and WHOQOL-BREF support the measurement properties, internal consistency, reliability and unidimensionality. This investigation will guide us using Rasch and CFA to find an appropriate modified questionnaire in terms of acceptability, validity, reliability and responsiveness. No prior studies have been undertaken using a similar approach to assess the community knowledge of MDs in Bangladesh.

Despite several benefits of this study, the methodology used suffers from some limitations. The study will be conducted in one rural area of Bangladesh, which may not delineate the portrait of the awareness of MDs and the level of psychological distress for all rural areas in Bangladesh. While we will attempt to capture the situation in Narail, the study would obviously need to be repeated in a random sample of other remote areas in order to be truly reflective of a national perspective.

This will be the first study to prompt a critical analysis of the psychometric properties of the WHOQOL-BREF and K10 questionnaires using Rasch analysis and CFA. The outcomes will deliver measurement properties, internal validity, reliability and unidimensionality of the scale. The findings will guide us to recommend further studies using validated questionnaires in clinical assessments using the appropriately targeted samples. The findings will discuss, in relation to the Bengali language and culture, social beliefs about MDs, and suggestions for improvements in mental health literacy and stigma towards mental health. Furthermore, we hope this study will enable the formation of an early intervention programme, targeted at those who are expected to diagnose with mental illness, such as mild or moderate levels of psychological distress. This programme, when developed, has the potential to reduce the likelihood of secondary effects such as loss of employment, school dropout, relationship collapse, disability and drug and alcohol problems. The study will also be able to suggest an appropriate programme for rural areas that require early intervention, which is important, as delay in getting help and support for mental health problems increases the likelihood of experiencing a difficult recovery.

\section{ETHICS AND DISSEMINATION}

Human Ethics Approval was received from the Swinburne University of Technology Human Ethics Committee in accordance with the tenets of the Declaration of Helsinki. Study participants provided written consent in order to participate. We anticipate that the findings will be of interest Ministry of Health Bangladesh and other similar international organisations who work in the rural area in Bangladesh. We also expect that the study will generate recommendations in relation to practice. Results of this research will be disseminated via scientific forums including peer-reviewed publications, community briefs and presentations at national and international conferences.

\section{KAP QUESTIONNAIRE}

A questionnaire will be adopted to collect data on participant's awareness and KAP regarding mental health, and data relevant to sociodemographic characteristics. Questions evaluating knowledge, attitude and practice of mental health were associated with categorical responses such as 'yes' or 'no'. There are seven items related to mental disorders (depression, anxiety, psychosis, drug addiction, dementia, bipolar disorder and Alzheimer's disease), which will be included in the questionnaire. Each of the mental health indicators consists of seven questions. For example,

1. Have you ever heard of depression? yes $=1, \mathrm{no}=0$.

2. If yes, please list at least one symptom of depression. Answer will be reported as 'at least one $=1$ ' and 'none $=0$ '.

3. Attitude towards mental health: if you or any of your friends or relatives have had any mental health problems, do they seek treatment? Possible responses were, yes $=1$, no $=0$.

4. If the response was 'yes', the question was 'where would they seek treatment?' with a possible response of 'medical doctor $=1$ ', 'counselling=2' or 'others, such as seek advice from spiritual person=3'.

5. The participants were asked whether they had any mental disorders by asking 'Do you suffer from depression?' with possible answers of 'yes $=1$ ' and 'no $=0$ '.

6. If the response was 'yes', the question was 'Do you take treatment?' with a possible response of 'yes $=1$ ' or 'no $=0$ '.

7. If the response was 'yes', the next question was 'where did you go for treatment?' with a possible response of 'medical doctor=1', 'psychological counselling=2' or 'others, such as seek advice from spiritual person $=3$

K10 questionnaire. ${ }^{51}$

WHOQOL-BREF questionnaire. ${ }^{63}$

Acknowledgements The authors acknowledge Dr Jason Skues for providing valuable feedback about the project. They particularly acknowledge the contribution of Md Rafiqul Islam, Md Sajibul Islam, Saburan Nesa and Arzan Hossain who will collect the data from the participant's households. Finally, they would like to express their gratitude to the study participants for their voluntary participation.

Contributors MNU and FMAI: jointly designed the study. MNU: drafted the manuscripts. SB, AAM and FMAl: contributed in writing the manuscripts. FMAl :supervised the overall preparation of the manuscript. All authors: read and approved the final manuscript.

Funding Data collection for this research project was funded by the Faculty of Health, Arts and Design (FHAD) of the Swinburne University Technology under the 
Research and Development Grant Scheme (RDGS). The funders had no role in the design of the study, data collection, analysis, interpretation of data or writing the manuscript.

\section{Competing interests None declared.}

Provenance and peer review Not commissioned; externally peer reviewed.

Open Access This is an Open Access article distributed in accordance with the Creative Commons Attribution Non Commercial (CC BY-NC 4.0) license, which permits others to distribute, remix, adapt, build upon this work non-commercially, and license their derivative works on different terms, provided the original work is properly cited and the use is non-commercial. See: http://creativecommons.org/ licenses/by-nc/4.0/

(C) Article author(s) (or their employer(s) unless otherwise stated in the text of the article) 2017. All rights reserved. No commercial use is permitted unless otherwise expressly granted.

\section{REFERENCES}

1. Tomlinson M, Swartz L, Daniels K. No health without mental health The global effort to improve population mental health. Rout Stud Pub HIth 2011:174-91.

2. Association AP. Diagnostic and statistical manual of mental disorders (DSM-5®): American Psychiatric Pub, 2013.

3. Whiteford HA, Degenhardt L, Rehm J, et al. Global burden of disease attributable to mental and substance use disorders: findings from the global burden of disease study 2010. Lancet 2013;382:1575-86.

4. Moussavi S, Chatterji S, Verdes E, et al. Depression, chronic diseases, and decrements in health: results from the World Health Surveys. Lancet 2007;370:851-8.

5. Patel V, Kleinman A. Poverty and common mental disorders in developing countries. Bull World Health Organ 2003;81:609-15.

6. Lamers F, van Oppen P, Comijs HC, et al. Comorbidity patterns of anxiety and depressive disorders in a large Cohort Study: the Netherlands Study of Depression and anxiety (NESDA). J Clin Psychiat 2011;72:341-8.

7. Bruckner TA, Scheffler RM, Shen G, et al. The mental health workforce gap in low- and middle-income countries: a needs-based approach. Bull World Health Organ 2011;89:184-94.

8. Hock RS, Or F, Kolappa K, et al. A new resolution for global mental health. Lancet 2012;379:1367-8.

9. Hosain GM, Chatterjee N, Ara N, et al. Prevalence, pattern and determinants of mental disorders in rural Bangladesh. Public Health 2007;121:18-24.

10. Islam MM, Ali M, Ferroni $P$, et al. Prevalence of psychiatric disorders in an urban community in Bangladesh. Gen Hosp Psychiatry 2003;25:353-7.

11. Hossain MD, Ahmed HU, Chowdhury WA, et al. Mental disorders in Bangladesh: a systematic review. BMC Psychiatry 2014;14:216

12. Kilkkinen A, Kao-Philpot A, O'Neil A, et al. Prevalence of psychological distress, anxiety and depression in rural communities in Australia. Aust J Rural Health 2007;15:114-9.

13. World Health Organization. The world health report: 2001. Mental health: new understanding, new hope. 2001. Geneva: WHO, 2001.

14. Demaio AR, Otgontuya D, de Courten M, et al. Exploring knowledge, attitudes and practices related to diabetes in Mongolia: a national population-based survey. BMC Public Health 2013;13:236.

15. Rani PK, Raman R, Subramani S, et al. Knowledge of diabetes and diabetic retinopathy among rural populations in India, and the influence of knowledge of diabetic retinopathy on attitude and practice. Rural Remote Health 2008;8:838.

16. Zaman MJ, Patel A, Jan S, et al. Socio-economic distribution of cardiovascular risk factors and knowledge in rural India. Int $J$ Epidemiol 2012;41:1302-14.

17. Islam FMA, Chakrabarti R, Islam SZ, et al. Factors associated with awareness, attitudes and Practices regarding Common Eye Diseases in the General Population in a Rural District in Bangladesh: the Bangladesh Population-based Diabetes and Eye Study (BPDES). PLoS One 2015;10:e0133043.

18. Islam FM, Chakrabarti R, Dirani M, et al. Knowledge, attitudes and practice of diabetes in rural Bangladesh: the Bangladesh Population based Diabetes and Eye Study (BPDES). PLoS One 2014;9:e110368.

19. Norris SL, Engelgau MM, Narayan KM. Effectiveness of selfmanagement training in type 2 diabetes: a systematic review of randomized controlled trials. Diabetes Care 2001;24:561-87.

20. Al-Maskari F, El-Sadig M, Al-Kaabi JM, et al. Knowledge, attitude and practices of diabetic patients in the United Arab Emirates. PLoS One 2013;8:e52857.
21. Mazzuca SA, Moorman NH, Wheeler ML, et al. The diabetes education study: a controlled trial of the effects of diabetes patient education. Diabetes Care 1986;9:1-10.

22. Jorm AF, Korten AE, Jacomb PA, et al. 'Mental health literacy': a survey of the public's ability to recognise mental disorders and their beliefs about the effectiveness of treatment. Med J Aust 1997;166:182-6.

23. Liu MC, Tirth S, Appasani R, et al. Knowledge and attitudes toward depression among community members in rural Gujarat, India. $J$ Nerv Ment Dis 2014;202:813-21.

24. Almanzar S, Shah N, Vithalani S, et al. Knowledge of and attitudes toward clinical depression among health providers in Gujarat, India. Ann Glob Health 2014;80:89-95.

25. Kuyken W, Orley J. Development of the Whoqol - Rationale and current status. Int J Ment Health 1994;23:24-56.

26. Chang KC, Wang JD, Tang HP, et al. Psychometric evaluation, using rasch analysis, of the WHOQOL-BREF in heroin-dependent people undergoing methadone maintenance treatment: further item validation. Health Qual Life Outcomes 2014;12:148.

27. Kuyken W, Orley J, Power M, et al. The World Health Organization Quality of Life assessment (WHOQOL): position paper from the World Health Organization. Soc Sci Med 1995;41:1403-9.

28. WHOQOL-Measuring quality of life. The World Health Orgnaization Quality of Life Instruments. 1997.

29. Silva SM, Corrêa FI, Faria CD, et al. Psychometric properties of the stroke specific quality of life scale for the assessment of participation in stroke survivors using the rasch model: a preliminary study. $J$ Phys Ther Sci 2015;27:389-92.

30. Dœbiec J, Goch A, Chmielewski H, et al. Effect of diabetes on neurological condition and quality of life of patients with ischaemic stroke. Atherosclerosis 1999;144:192-92.

31. Jia H, Zack MM, Thompson WW. The effects of diabetes, hypertension, asthma, heart disease, and stroke on quality-adjusted life expectancy. Value Health 2013;16:140-7.

32. Richardson J, Sinha K, lezzi A, et al. Modelling utility weights for the Assessment of Quality of Life (AQoL)-8D. Qual Life Res 2014;23:2395-404

33. Berzon RA, Donnelly MA, Simpson RL, et al. Quality of life bibliography and indexes: 1994 update. Qual Life Res 1995;4:547-69

34. Wahl AK, Rustøen T, Hanestad BR, et al. Quality of life in the genera Norwegian population, measured by the Quality of Life Scale (QOLS-N). Qual Life Res 2004;13:1001-9.

35. Ohaeri JU, Awadalla AW, El-Abassi AHM, et al. Confirmatory factor analytical study of the WHOQOL-Bref: experience with sudanese general population and psychiatric samples. BMC Med Res Methodol 2007;7:37.

36. Redko C, Rogers N, Bule L, et al. Development and validation of the somali WHOQOL-BREF among refugees living in the USA. Qual Life Res 2015;24:1503-13.

37. Flanagan JC. Measurement of quality of life: current state of the art. Arch Phys Med Rehabil 1982;63:56-9.

38. Flanagan JC. A research approach to improving our quality of life. Am Psychol 1978;33:138-47.

39. Development of the World Health Organization WHOQOL-BREF quality of life assessment. The WHOQOL Group. Psychol Med 1998;28:551-8.

40. Izutsu $\mathrm{T}$, Tsutsumi $\mathrm{A}$, Islam $\mathrm{A}$, et al. Validity and reliability of the Bangla version of WHOQOL-BREF on an adolescent population in Bangladesh. Qual Life Res 2005;14:1783-9.

41. Tsutsumi A, Izutsu T, Kato S, et al. Reliability and validity of the Bangla version of WHOQOL-BREF in an adult population in Dhaka, Bangladesh. Psychiatry Clin Neurosci 2006;60:493-8.

42. Zeldenryk L, Gordon S, Gray M, et al. Cognitive testing of the WHOQOL-BREF Bangladesh tool in a northern rural Bangladeshi population with lymphatic filariasis. Qual Life Res 2013;22:1917-26.

43. Laskar MS, Rahaman MM, Akhter A, et al. Quality of Life of Arsenicosis Patients in an Arsenic-Affected Rural Area in Bangladesh. Arch Environ Occup Health 2010;65:70-6.

44. Bradley KD. Book review: applying the Rasch Model: fundamental measurement in the Human Sciences. Organ Res Methods 2005:8:249-50.

45. Bartholomew D. Fundamentals of Item Response Theory Hambleton, Rk, Swaminathan, H, Rogers, Hj. Brit J Math Stat Psy 1993;46:184-5.

46. Raykov T, Marcoulides GA. Fundamentals and models of Item Response Theory. Introduction to Psychometric Theory 2011:269-304

47. Sunderland M, Mahoney A, Andrews G. Investigating the factor structure of the Kessler Psychological Distress Scale in Community 
and clinical samples of the australian Population. $J$ Psychopathol Behav Assess 2012;34:253-9.

48. Beck AT, Ward CH, Erbaugh J, et al. An inventory for measuring depression. Arch Gen Psychiatry 1961:4:561.

49. Zigmond AS, Snaith RP. The hospital anxiety and depression scale. Acta Psychiatr Scand 1983;67:361-70.

50. Parkitny L, McAuley J. The depression anxiety stress Scale (DASS). $J$ Physiother 2010;56:204-04.

51. Kessler RC, Andrews G, Colpe LJ, et al. Short screening scales to monitor population prevalences and trends in non-specific psychological distress. Psychol Med 2002;32:959-76.

52. Kessler RC, Barker PR, Colpe LJ, et al. Screening for serious mental illness in the general population. Arch Gen Psychiatry 2003;60:184-9.

53. Andrews $\mathrm{G}$, Slade T. Interpreting scores on the Kessler Psychological Distress Scale (K10). Aust N Z J Public Health 2001;25:494-7.

54. Cairney J, Veldhuizen S, Wade TJ, et al. Evaluation of 2 measures of psychological distress as screeners for depression in the general population. Can J Psychiatry 2007;52:111-20.

55. Oakley Browne MA, Wells JE, Scott KM, et al.The Kessler Psychological Distress Scale in Te Rau Hinengaro: the New Zealand Mental Health Survey. Aust N Z J Psychiatry 2010;44:314-22.

56. Furukawa TA, Kawakami N, Saitoh M, et al. The performance of the Japanese version of the K6 and K10 in the World Mental Health Survey Japan. Int J Methods Psychiatr Res 2008;17:152-8.

57. Adult literacy rate in Bangladesh. 2015.
58. Saxena S, Carlson D, Billington R, et al. The WHO quality of life assessment instrument (WHOQOL-Bref): the importance of its items for cross-cultural research. Qual Life Res 2001;10:711-21.

59. District Statistics. Secondary District Statistics 2017. $2017 \mathrm{http} / /$ www.bbs.gov.bd/WebTestApplication/userfiles/Image/District\% 20Statistics/Narail.pdf

60. Bangladesh Bureau of Statistics. Population and Housing Census. 2010.

61. Hossain MD, Ahmed HU, Chowdhury WA, et al. Mental disorders in Bangladesh: a systematic review. BMC Psychiatry 2014;14:216.

62. Reavley NJ, Jorm AF. National Survey of Mental Health literacy and stigma. Department of Health and Ageing, Canberra 2011.

63. Harper A, Power M, Grp W. Development of the World Health Organization WHOQOL-BREF quality of life assessment. the WHOQOL Group. Psychol Med 1998;28:551-8.

64. Brislin RW. Back-Translation for Cross-Cultural Research. J Cross Cult Psychol 1970;1:185-216.

65. Permission to use WHOQOL-100 and/or WHOQOL-BREF questionnaires. 2015.

66. Cheng YH, Chi I, Boey KW, et al. Self-rated economic condition and the health of elderly persons in Hong Kong. Soc Sci Med 2002;55:1415-24.

67. Serraglio A, Carson N, Ansari Z. Comparison of health estimates between Victorian Population Health surveys and National Health surveys. Aust N Z J Public Health 2003;27:645-8. 